\title{
Chiang Mai University Health Worker Study aiming toward a better understanding of noncommunicable disease development in Thailand: methods and description of study population
}

This article was published in the following Dove Press journal:

Clinical Epidemiology

13 August 2014

Number of times this article has been viewed

Chaisiri Angkurawaranon ${ }^{1,2}$

Anawat Wisetborisut ${ }^{2}$

Wichuda Jiraporncharoen ${ }^{2}$

Surinporn Likhitsathian ${ }^{3}$

Ronnaphob Uaphanthasath ${ }^{2}$

Patama Gomutbutra ${ }^{2}$

Surin Jiraniramai ${ }^{2}$

Chawin Lerssrimonkol ${ }^{2}$

Apinun Aramrattanna ${ }^{2}$

Pat Doyle'

Dorothea Nitsch'

'Department of Non-Communicable Disease Epidemiology, Faculty of Epidemiology and Population Health, London School of Hygiene and Tropical Medicine, London, UK ${ }^{2}$ Department of Family Medicine, Faculty of Medicine, Chiang Mai University, Chiang Mai, Thailand; ${ }^{3}$ Department of Psychiatry, Faculty of Medicine, Chiang Mai University, Chiang Mai, Thailand
Correspondence: Chaisiri

Angkurawaranon

London School of Hygiene and Tropical Medicine, Keppel Street, London WCIE 7HT, UK

Tel +44207927 2254

Fax +44 2075806897

Email chaisiri.angkurawaranon@Ishtm.

ac.uk; chaisiri.a@cmu.ac.th
Background: Urbanization is considered to be one of the key drivers of noncommunicable diseases (NCDs) in Thailand and other developing countries. These influences, in turn, may affect an individual's behavior and risk of developing NCDs. The Chiang Mai University (CMU) Health Worker Study aims to provide evidence for a better understanding of the development of NCDs and ultimately to apply the evidence toward better prevention, risk modification, and improvement of clinical care for patients with NCDs and NCD-related conditions.

Methods: A cross-sectional survey of health care workers from CMU Hospital was conducted between January 2013 and June 2013. Questionnaires, interviews, and physical and laboratory examinations were used to assess urban exposure, occupational shift work, risk factors for NCDs, self-reported NCDs, and other NCD-related health conditions.

Results: From 5,364 eligible workers, 3,204 participated (59.7\%). About $11.1 \%$ of the participants had high blood pressure (systolic blood pressure $\geq 140 \mathrm{mmHg}$ or diastolic blood pressure $\geq 90 \mathrm{mmHg}$ ) and almost $30 \%$ were considered to be obese (body mass index $\geq 25 \mathrm{~kg} / \mathrm{m}^{2}$ ). A total of $2.3 \%$ had a high fasting blood glucose level ( $\geq 126 \mathrm{mg} / \mathrm{dL})$, and the most common abnormal lipid profile was high low-density lipoprotein ( $\geq 160 \mathrm{mg} / \mathrm{dL})$, which was found in $19.2 \%$ of participants.

Discussion: The study of health workers offers three potential advantages. The first is that the study of migrants was possible. Socioenvironmental influence on NCD risk factors can be explored, as changes in environmental exposures can be documented. Second, it allows the investigators to control for access to care. Access to care is potentially a key confounder toward understanding the development of NCDs. Lastly, a study of health personnel allows easy access to laboratory investigations and potential for long-term follow-up. This enables ascertainment of a number of clinical outcomes and provides potential for future studies focusing on therapeutic and prognostic issues related to NCDs.

Keywords: urbanization, noncommunicable disease, risk factors, Thailand

\section{Background}

Thailand, like many middle-income countries, has undergone rapid sociocultural and environmental changes within the last decades, and with them there has been a growing burden of noncommunicable diseases (NCDs). ${ }^{1}$ Sociocultural changes thought to be associated with urbanization, globalization, and an aging population are considered potential drivers for the growing burden of NCDs. ${ }^{2}$ At an ecological level, there is 
evidence from Thailand that urbanization is associated with NCD mortality. ${ }^{3}$ At an individual level, there is further evidence that current sociocultural and environmental changes in Thailand are associated with many behavioral changes, such as consumption of fatty food and lack of exercise. ${ }^{4}$ In turn, these behavioral changes may lead to increases of some physiological risk factors for NCDs, such as obesity and high blood pressure. ${ }^{5}$ However, there is still limited evidence on whether urbanization leads to biomarker changes preceding the development of NCDs, and the mechanisms behind such susceptibility to NCDs in Thailand remain unknown. Evidence from Western countries suggests that although socioeconomic and cultural changes may lead to increased risk of developing NCDs, the same socioeconomic and cultural changes may also be associated with higher income and better access to care and life choices that may decrease risk of developing NCDs. ${ }^{6}$

\section{Conceptual framework of study}

The conceptual framework for this research was adapted from the framework on globalization and health (Figure 1). ${ }^{7}$ In this study we considered urbanization as the key driver of sociocultural and environmental change in Thailand. The effect of urbanization on the development of NCDs was considered at two levels: the population level and the individual level. At the population level, urbanization could influence health through environmental and sociocultural norms, and could also influence other health-related sectors such as education and trade, along with the national economy, politics, and society. These population level factors could subsequently influence an individual's health beliefs and behavior. For individual level factors, the risk factors for NCDs were taken from the World Health Organization's (WHO) framework. ${ }^{8}$ The individual level determinants included the individual's behavioral risk factors for NCDs, the individual's socioeconomic status, and the health care system that the individual is in. Health care systems would reflect the individual's access to care and availability of medication. Ultimately, all these pathways would be expected to mediate changes in an individual's biological/physiological risk factor profile, which is depicted by the farthest left pathway in Figure 1.

\section{Aim of the Chiang Mai University Health Worker Study}

The overall aim of the Chiang Mai University (CMU) Health Worker Study is to provide evidence for a better

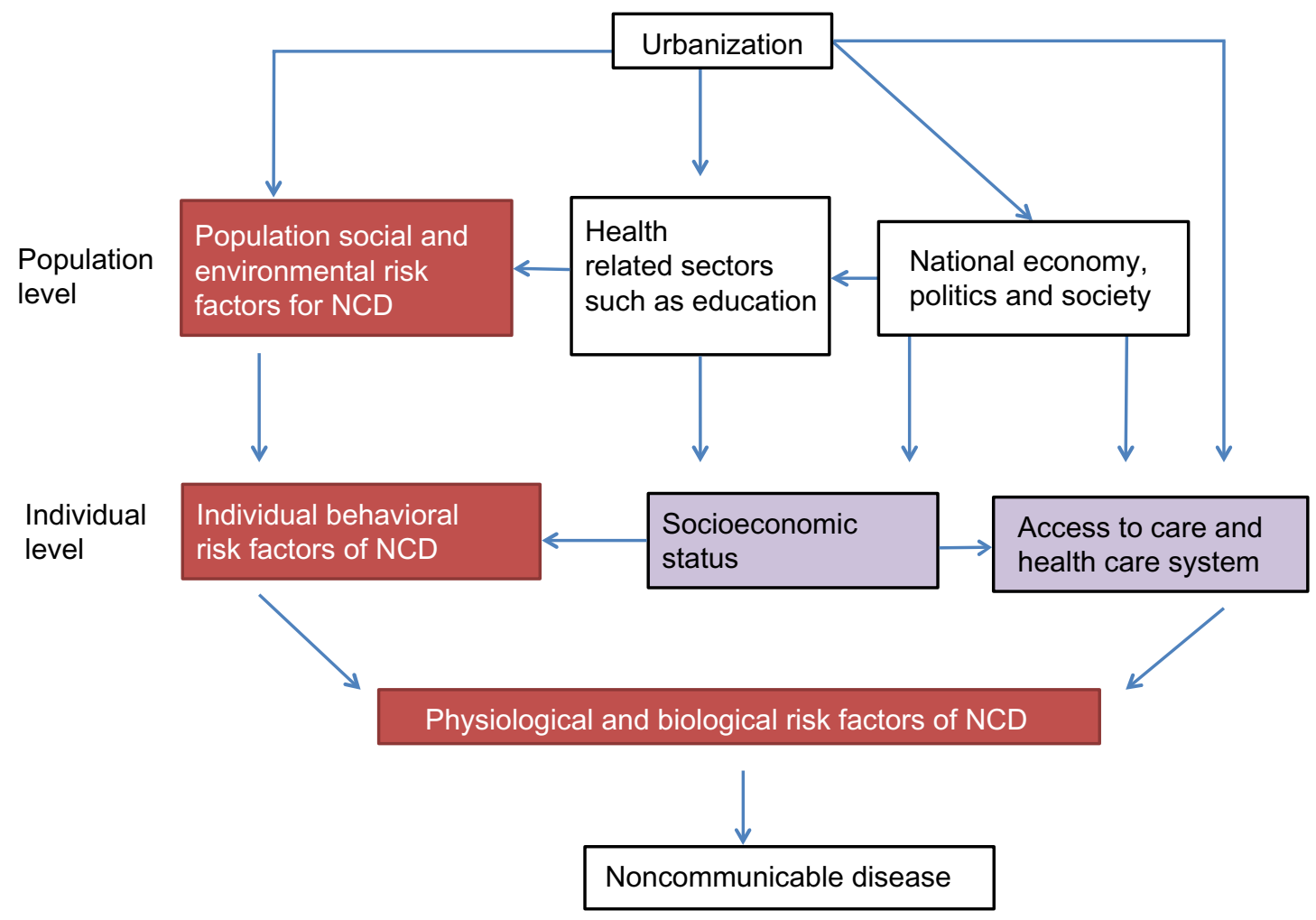

Figure I Conceptual framework for drivers of noncommunicable disease (NCD).

Notes: Factors that are mediators on causal pathways between urbanization and NCD. $\square$ More distal risk factors that may introduce residual confounding in the association between individual behavioral risk factors and NCD risk. 
understanding of the development of NCDs in contemporary Thailand, and ultimately to apply the evidence toward better prevention, risk modification, and improvement of clinical care for patients with NCDs and NCD-related conditions.

The specific objectives of the study are:

1. To investigate the difference in behavioral and biological risk factors for NCDs among those with different urban exposures;

2. To investigate the difference in changes in biological risk factors for NCDs among those with different urban exposures;

3. To investigate the association between occupational factors such as shift work with burnout and depression;

4. To investigate the patterns of substance use, such as sedative use and its association with alcohol consumption and smoking.

The objective of this paper is to describe the study methods and present the sociodemographic characteristics of the study population.

\section{Methods Design}

This was an occupationally based cross-sectional survey.

\section{Setting and participants}

Between 2012 and 2013 a team of investigators from the Faculty of Medicine of CMU and the London School of Hygiene and Tropical Medicine developed an NCD screening protocol that would be accessible to all health care workers employed by the Faculty of Medicine of CMU, irrespective of age, health status, or type of medical insurance. The Faculty of Medicine of CMU and Maharaj Nakorn Chiang Mai Hospital employs over 5,000 health care workers. As part of hospital and government policy, health workers at CMU Hospital are offered periodic health checkups. Attendance of health workers at these checkups was used to deliver the health screening protocol between January 2013 and June 2013.

\section{Recruitment strategy}

The study used an online recruitment and enrollment program. A pilot study using online electronic enrollment and a questionnaire had been conducted in $2008 .^{9}$ The topics in the 2008 survey included known history of chronic diseases, lifestyles and behavior, and exposure to occupational hazards. The pilot study yielded a $77 \%$ response rate.

For this study, 1 month before enrollment, promotional videos and posters were created and distributed in the official faculty website, by email, and newsletter. The initial enrollment period was from the beginning of January 2013 to early February 2013. The short recruitment time used initially was so that the study team could coordinate and plan a realistic timetable for the physical examination and laboratory investigations that would follow from March 2013 to June 2013. A second enrollment started in the middle of March 2013 and ended in May 2013 to allow for additional participants who may have missed the initial enrollment period. During the second enrollment, in addition to the recruitment strategies previously employed, a new poster stating that the enrollment period had been extended was used as desktop wallpaper on all hospital-operated computers. For participants who did not have easy access to a computer at work, two computers were set aside to help with enrollment at the Health Promotion Unit in the hospital. In addition, a paper format of the enrollment form was also able to be requested, and entered online at a later convenience. A flowchart of the recruitment process is demonstrated in Figure 2.

\section{Data collection}

The data collection consisted of two parts. The first was the online registration with a subsequent online questionnaire. The second part was when the participants came in for their interview and received a physical examination, along with laboratory investigations (Figure 3).

\section{Online registration, consent, and online questionnaire}

For the online registration, health workers could log in online using their Thai national identification number. This was used to confirm their working status within the hospital. A study information sheet and consent form was presented on-screen. If consent was given, the participants were asked to fill in their basic demographic information and details of current shift work status and risk of burnout, using Maslach Burnout Inventory questionnaires. ${ }^{10}$ They could then choose from an allocated time and date to come in for their interview and examination.

\section{Face-to-face interview with examination} and sample collection

Participants were asked to fast for at least 8 hours before the day of their examination. On the day of their examination they were assigned a study identification number and given a set of self-administered questionnaires. The questionnaires covered three topics:

1. Risk of harm from substance use using the WHO Alcohol, Smoking and Substance Involvement Screening Test (ASSIST) questionnaire; ${ }^{11}$ 


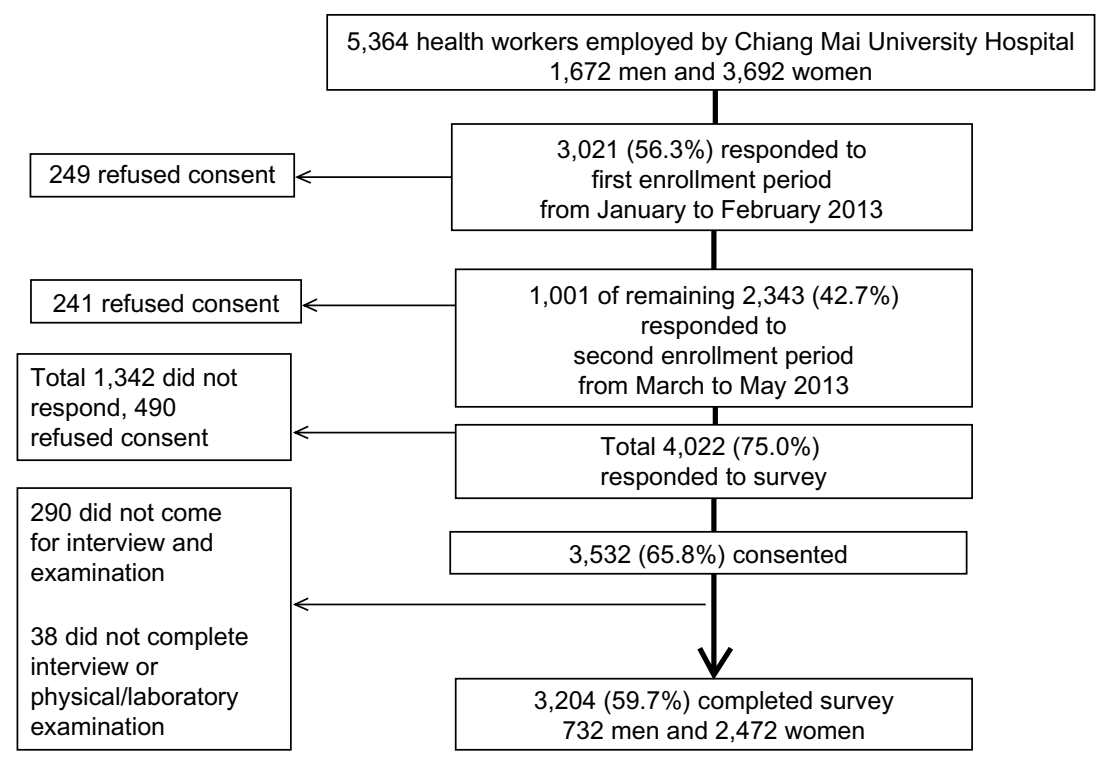

Figure 2 Enrollment process and response.

2. Depression screening using the Patient Health Questionnaire-9 (PHQ-9); ${ }^{12}$

3. Health-related quality of life using the 36-Item Short Form Health Survey (SF-36). ${ }^{13}$

The participants were later interviewed by members of the research team. All face-to-face interviews were carried out by members who were not working at CMU Hospital. Using an online computer system, the participant and researcher would together enter information about the participant's previous migration history and risk factors for NCDs, based on the WHO

\begin{tabular}{|c|}
\hline Consented and registered online \\
\hline $\begin{array}{c}\text { 1. First part of data collection (online) } \\
\text { Completion of questionnaire covering } \\
\text { basic demographic details, } \\
\text { shiftwork information and burnout }\end{array}$ \\
\hline 2. Second part of data collection \\
\hline 2.1 Self-administered questionnaire covered \\
risk of harm from substance use, \\
depression and quality of life
\end{tabular}

Figure 3 Flow chart of data collection process.
STEPwise approach to chronic disease risk factor surveillance (STEPS) instrument. ${ }^{14}$

At the examination area, standing height (without shoes), weight, and leg length were measured using a portable stadiometer, an electronic scale, and a standard measuring tape. Waist circumference, hip circumference, and leg length were measured to the nearest $0.1 \mathrm{~cm}$. Waist circumference was measured at the midway point between the lowest palpable rib and the anterior superior iliac crest. Hip circumference was measured around the widest part of the buttock. Leg length was measured from the anterior superior iliac crest to the medial malleolus. All measurements were carried out by trained investigators. Three blood pressure readings were taken 5 minutes apart using an $\mathrm{ADC}^{\circledR}$ digital e-sphyg ${ }^{\mathrm{TM}} 2$ nonmercury sphygmomanometer (American Diagnostic Corporation, Hauppauge, NY, USA). Two different cuff sizes were available, and the machines were calibrated every 2 months. Venous blood samples were drawn and processed at the Central Diagnostic Laboratory in CMU Hospital. The complete list of laboratory examinations, which includes fasting blood glucose (FBG) and lipid profiles, along with the methods used, can be found in Table 1. Ten percent of blood samples, chosen at random, were aliquoted and stored in an ultralow temperature $\left(-70^{\circ} \mathrm{C}\right)$ freezer for future use/ validation studies.

\section{Variables of interest}

The factors that were assessed by this study were urban/ occupational influences, individual risk factors for NCDs, and self-reported NCDs and other NCD-related health conditions 
Table I List of laboratory examinations and methods used

\begin{tabular}{|c|c|c|}
\hline Investigation & Sample & Methods used \\
\hline $\begin{array}{l}\text { Complete blood } \\
\text { count }\end{array}$ & $\begin{array}{l}\text { Ethylenediaminetetraacetic } \\
\text { acid blood }\end{array}$ & $\begin{array}{l}\text { Automated cell } \\
\text { counter }\end{array}$ \\
\hline $\begin{array}{l}\text { Fasting blood } \\
\text { glucose }\end{array}$ & Clotted blood & $\begin{array}{l}\text { Glucose } \\
\text { hexokinase }\end{array}$ \\
\hline Total cholesterol & Clotted blood & $\begin{array}{l}\text { Direct enzymatic } \\
\text { method }\end{array}$ \\
\hline $\begin{array}{l}\text { Low-density } \\
\text { lipoproteins }\end{array}$ & Clotted blood & $\begin{array}{l}\text { Direct enzymatic } \\
\text { method }\end{array}$ \\
\hline $\begin{array}{l}\text { High-density } \\
\text { lipoproteins }\end{array}$ & Clotted blood & $\begin{array}{l}\text { Direct enzymatic } \\
\text { method }\end{array}$ \\
\hline Triglycerides & Clotted blood & $\begin{array}{l}\text { Direct enzymatic } \\
\text { method }\end{array}$ \\
\hline $\begin{array}{l}\text { Blood urea } \\
\text { nitrogen }\end{array}$ & Clotted blood & $\begin{array}{l}\text { Urease enzymatic } \\
\text { method }\end{array}$ \\
\hline Creatinine & Clotted blood & $\begin{array}{l}\text { Modified Jaffe's } \\
\text { method }\end{array}$ \\
\hline $\begin{array}{l}\text { Aspartate } \\
\text { aminotransferase }\end{array}$ & Clotted blood & Kinetic method \\
\hline $\begin{array}{l}\text { Alanine } \\
\text { aminotransferase }\end{array}$ & Clotted blood & Kinetic method \\
\hline $\begin{array}{l}\text { Alkaline } \\
\text { phosphatase }\end{array}$ & Clotted blood & Kinetic method \\
\hline Uric acid & Clotted blood & $\begin{array}{l}\text { Urease enzymatic } \\
\text { method }\end{array}$ \\
\hline $\begin{array}{l}\text { Urinalysis } \\
\text { Chest X-ray }\end{array}$ & Mid-void urine sample & Automated \\
\hline
\end{tabular}

Notes: The Ministry of Public Health, Thailand provides a list of accredited laboratory investigations and methods used to obtained ISO 15/89. http://webdb. dmsc.moph.go.th/ifc_qa/DBQA/ifc_qa/userfiles/I 5 189\%204027_TH.pdf.

and outcomes. Population and occupational factors consisted of lifetime urban exposure and exposure to shift work. Risk factors for NCDs consisted of four behavioral (unhealthy diet, physical inactivity, and alcohol, and tobacco use) and four biological/physiological (increased blood pressure, obesity, hyperlipidemia, and hyperglycemia) risk factors. The absence or presence of an NCD (cardiovascular disease, diabetes, chronic respiratory disease, and cancer) was assessed using self-report. Other health-related conditions consisted of burnout, depression, substance use, and health-related quality of life

\section{Key variable definitions}

1. Urban exposure: The United Nations defines an urban agglomeration as "the built-up or densely populated area containing the city proper, suburbs and continuously settled commuter areas. It may be smaller or larger than a metropolitan area; it may also comprise the city proper and its suburban fringe or thickly settled adjoining territory." ${ }^{15}$ For our study, districts in Bangkok and the ten districts in the Chiang Mai metropolitan area (Figure 4) were considered urban. The rest of the districts in Thailand were classified as rural. By tracking the area of residence during crucial development points, urban and rural exposure, total years of urban exposure, and proportion of lifetime exposure to the urban area could be calculated.

2. Behavioral risk factors for NCDs: All variables were derived through interviews using the WHO STEPS questionnaire. Alcohol consumption was defined as having consumed alcohol within the past 12 months. A heavy drinking pattern was defined as having more than five standard drinks per sitting for men and more than four standard drinks per sitting for women. Smoking status was classified according to whether participants currently used tobacco product daily. An unhealthy diet was classified using standard units of fruit and vegetables consumed per week. It is suggested that five units per day is the minimal requirement. Physical inactivity was classified using the WHO recommendation on physical activity for health. ${ }^{16}$ Throughout the week, an adult should do at least 75 minutes of vigorous-intensity physical activity or 150 minutes of moderate-intensity physical activity or the equivalent of 600 metabolic equivalent minutes.

3. Biological/physiological risk factors for NCDs: The average of the second and third blood pressure reading was used as the blood pressure for each participant. Increased blood pressure was defined as systolic blood pressure (SBP) $\geq 140 \mathrm{mmHg}$ or diastolic blood pressure (DBP) $\geq 90 \mathrm{mmHg}$. Body mass index (BMI), calculated from taking the weight (in $\mathrm{kg}$ ) and dividing by height (in meters) squared, was used to define obesity. Using standard Asian criteria, ${ }^{17}$ a BMI of $\geq 25$ was considered the cutoff point for obesity. Hyperglycemia was measured using FBG. A participant was considered to have high blood glucose if their blood glucose was $\geq 126 \mathrm{mg} / \mathrm{dL}$. Low-density lipoprotein (LDL), high-density lipoprotein (HDL), and triglycerides were used as measures of dyslipidemia. A participant was considered to have high LDL cholesterol if their LDL level was $\geq 160 \mathrm{mg} / \mathrm{dL}$. The HDL cutoff points for low HDL were $<40 \mathrm{mg} / \mathrm{dL}$ in men and $<50 \mathrm{mg} / \mathrm{dL}$ in women. The cutoff point for high triglyceride level was $\geq 150 \mathrm{mg} / \mathrm{dL}$.

\section{Data entry and quality control}

Members of the research team were trained to perform interviews and examinations by the lead investigators. All materials/questionnaires used in the study were translated into Thai and were tested for validity in the Thai population 


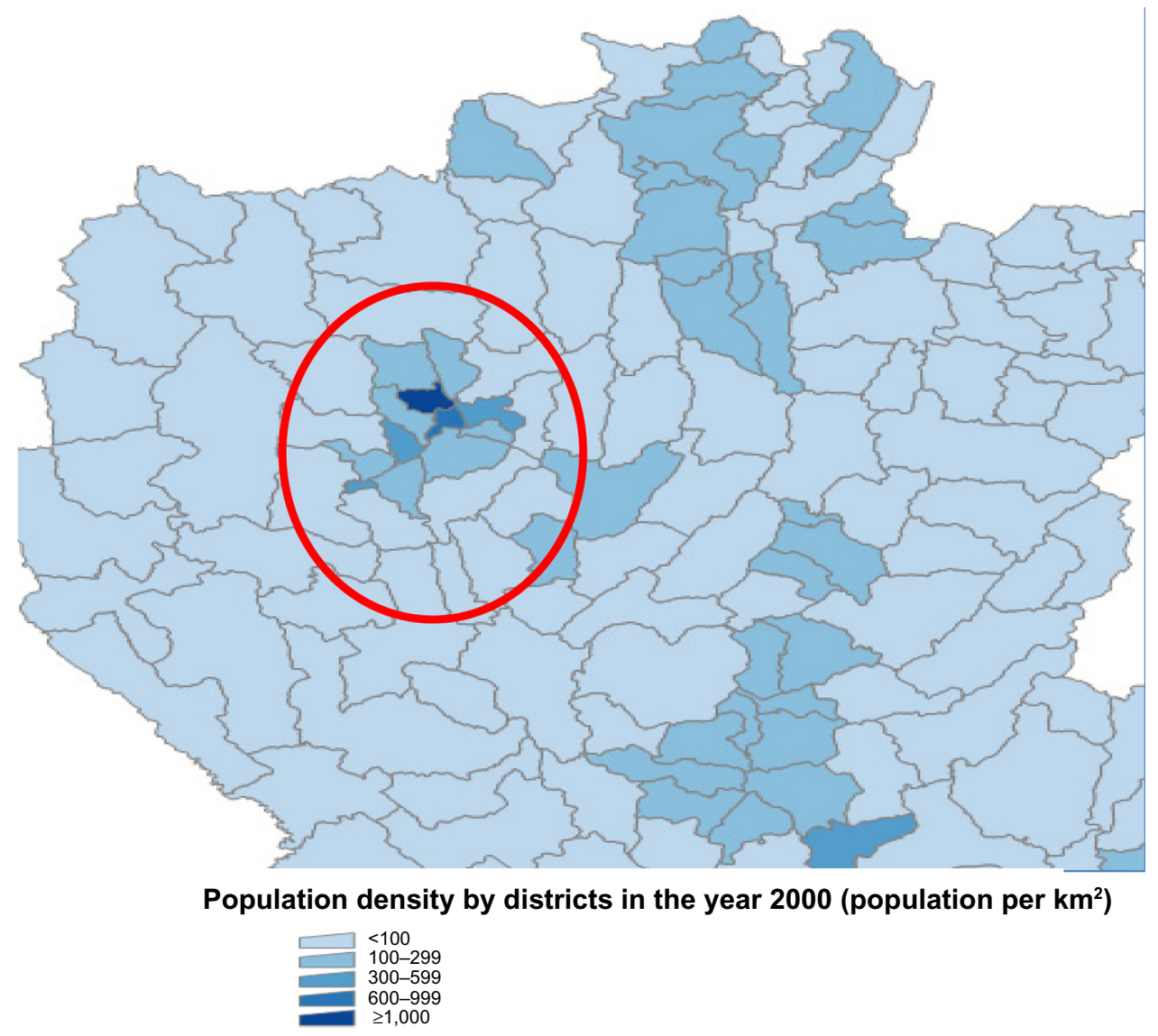

Figure 4 Ten districts in the Chiang Mai metropolitan area.

or have been published in past literature. ${ }^{18-22}$ Source documents from questionnaires and the physical examination were scanned and entered into the research database using a double entry system. All laboratory investigations were processed by the Central Diagnostic Laboratory in CMU Hospital. The laboratory undergoes a routine internal and external quality control process and has been accredited with International Organization for Standardization (ISO) 15189:2007.

To obtain laboratory results from the hospital's network, the study identification numbers and hospital numbers were linked using an electronic barcode system. Once linked to laboratory results, the hospital number and Thai national identification number were stripped from the research database. The research database was stored within the CMU Faculty of Medicine's intranet system and accessible only to members of the research team.

\section{Power calculations}

Using the 2008 pilot data, a conservative estimate for the ratio between urban group (health care workers born in an urban area) and rural to urban migrant group (health care workers born in a rural area) was 4:1. Assuming a similar compliance rate of $80 \%$, it was estimated that 3,200 participants would be classified as urban and 800 participants would be classified as rural to urban migrants. Given the assumed number of participants and results from the pilot study, it was estimated that the study would have $92 \%$ power to detect differences in BMI and $85 \%$ power to detect differences in SBP.

\section{Ethics}

The study was approved by the Faculty of Medicine of CMU (No 069/2012) and the London School of Hygiene and Tropical Medicine's ethical review boards (Ref: 6521).

\section{Analysis plan}

Different multivariable regression models will be built by carefully grouping sets of explanatory variables using the framework previously described in Figure 1. A life course approach and analysis ${ }^{23}$ will also be taken to explore the possible mechanisms for association between urbanization and NCD risk factors. A detailed analysis plan for each of the objectives will be presented in individual publications. For this paper, sociodemographic characteristics were summarized using descriptive statistics. 


\section{Results}

\section{Response rates}

As of July 2013 there were 5,364 people working for the Faculty of Medicine of CMU. A total of 4,022 (75.0\%) responded to the survey and $3,532(65.8 \%)$ consented to participate in the study. In the end, 3,204 (59.7\%) completed the entire data collection process (Figure 2). The study sample represented $43.7 \%$ of all male and $66.9 \%$ of all females working for the Faculty of Medicine of CMU and Maharaj Nakorn Chiang Mai Hospital. Using records from the faculty's official personnel database, we found that our study population represented the entire source population well, in terms of age and education status, but men and certain occupational groups such as doctors and dentists may have been under-represented (Table 2).

Table 2 Comparison of characteristics between study population and source population using the Chiang Mai University Hospital's official personnel database

\begin{tabular}{|c|c|c|}
\hline & $\begin{array}{l}\text { Study } \\
\text { population }\end{array}$ & $\begin{array}{l}\text { Source } \\
\text { population }\end{array}$ \\
\hline Number & $3,188^{\mathrm{a}}$ & 5,364 \\
\hline$\%$ female & 77.3 & 68.8 \\
\hline Mean age, years (standard deviation) & $39.7(10.7)$ & $40.5(11.0)$ \\
\hline \multicolumn{3}{|l|}{ Age distribution (\%) } \\
\hline$<25$ years & 10.7 & 8.8 \\
\hline $25-30$ years & 13.6 & 14.3 \\
\hline $30-35$ years & 13.5 & 12.7 \\
\hline $35-40$ years & 14.0 & 12.6 \\
\hline $40-45$ years & 11.7 & 10.9 \\
\hline $45-50$ years & 16.2 & 15.4 \\
\hline $50-55$ years & 12.0 & 13.9 \\
\hline $55-60$ years & 8.3 & 10.5 \\
\hline$>60$ years & 0.5 & 0.6 \\
\hline \multicolumn{3}{|l|}{ Job position (\%) } \\
\hline Special advisor & 0.0 & $<0.1$ \\
\hline Instructor (doctor of medicine) & 1.8 & 6.4 \\
\hline Instructor (not a doctor of medicine) & 1.2 & 1.9 \\
\hline Doctor/dentist & 0.7 & 5.8 \\
\hline Pharmacist & 2.1 & 2.2 \\
\hline Nurse & 38.7 & 31.1 \\
\hline Nurse aide & 13.2 & 12.2 \\
\hline Other health professionals & 2.8 & 3.0 \\
\hline Nonhealth professionals & 7.1 & 6.4 \\
\hline Administration officers & 4.1 & 3.9 \\
\hline Workers & 28.2 & 26.9 \\
\hline \multicolumn{3}{|l|}{ Highest education (\%) } \\
\hline Elementary school & 4.0 & 4.3 \\
\hline Early secondary school & 6.3 & 6.4 \\
\hline Late secondary school & 13.6 & 12.9 \\
\hline Bachelor's degree & 66.5 & 62.0 \\
\hline Master's degree & 6.7 & 6.3 \\
\hline $\mathrm{PhD} /$ equivalent & 2.8 & 8.0 \\
\hline
\end{tabular}

Note: ${ }^{2} 16$ participants were included in the research database but were not in the personnel database as of July 2013 when the analysis was conducted.

\section{Characteristics of the study population}

Of 3,204 participants who completed the entire survey, 732 participants were male (22.8\%) and 2,472 (77.2\%) were female. The mean age of the study population was 40.2 years. Nurses represented the largest occupation group in the survey (38.8\%). The majority of the participants had at least a bachelor's degree (64.6\%). A total of $41.8 \%$ of the workers were born outside Bangkok or Chiang Mai metropolitan area (Table 3). The majority of participants were not currently smoking at the time of the survey $(93.8 \%)$, but more than half had consumed alcohol within 12 months. Only $14.3 \%$ had at least five servings of fruit and/or vegetables per day, and $52.1 \%$ had an appropriate physical activity level as recommended by the WHO. Men were more likely to smoke and drink. They were also less likely to meet the recommended portions of fruit/vegetable consumption but were more likely to meet the requirement for physical activity

Table 3 Demographic characteristics of participants in the Chiang Mai University Health Worker Study

\begin{tabular}{|c|c|c|c|}
\hline Characteristics & $\begin{array}{l}\text { Total } \\
\mathrm{N}=3,204\end{array}$ & $\begin{array}{l}\text { Female } \\
N=2,472\end{array}$ & $\begin{array}{l}\text { Male } \\
\mathrm{N}=732\end{array}$ \\
\hline $\begin{array}{l}\text { Mean age, years (standard } \\
\text { deviation) }\end{array}$ & $40.2(10.7)$ & $40.1(10.9)$ & $40.6(9.9)$ \\
\hline \multicolumn{4}{|l|}{ Age group: N (\%) } \\
\hline$<30$ years & $677(2 \mathrm{I} .1)$ & $564(22.8)$ & $113(15.4)$ \\
\hline $30-40$ years & $878(27.4)$ & $642(26.0)$ & $236(32.2)$ \\
\hline $40-50$ years & $876(27.3)$ & $672(27.2)$ & $204(27.9)$ \\
\hline$>50$ years & $773(24.1)$ & $594(24.0)$ & $179(24.4)$ \\
\hline Sex: female: N (\%) & $2,472(77.1)$ & $2,472(100)$ & $0(0)$ \\
\hline \multicolumn{4}{|l|}{ Job position: N (\%) } \\
\hline $\begin{array}{l}\text { Instructors/doctors/ } \\
\text { dentists }\end{array}$ & 118 (3.7) & 7I (2.9) & $47(6.4)$ \\
\hline Nurses & $\mathrm{I}, 236(38.6)$ & $\mathrm{I}, 166(47.2)$ & $70(9.6)$ \\
\hline $\begin{array}{l}\text { Other health } \\
\text { professionals }\end{array}$ & $660(20.6)$ & $548(22.2)$ & $112(15.3)$ \\
\hline $\begin{array}{l}\text { Administration officers } \\
\text { and nonhealth professiona }\end{array}$ & $356(11.1)$ & $259(10.5)$ & $97(13.2)$ \\
\hline Workers & $834(26.0)$ & $428(17.3)$ & $406(55.5)$ \\
\hline \multicolumn{4}{|l|}{ Highest education: N (\%) } \\
\hline Below bachelor's degree & $\mathrm{I}, \mathrm{I} 34(35.4)$ & $721(29.2)$ & $4 \mid 3(56.4)$ \\
\hline Bachelor's degree & $\mathrm{I}, 690(52.7)$ & $\mathrm{I}, 432(57.9)$ & $258(35.2)$ \\
\hline $\begin{array}{l}\text { Higher than bachelor's } \\
\text { degree }\end{array}$ & $380(11.9)$ & $319(12.9)$ & $61(8.3)$ \\
\hline \multicolumn{4}{|c|}{ Household income per month (Baht) ${ }^{\mathrm{a}} \mathrm{N}(\%)$} \\
\hline$<20,000$ & $\mathrm{I}, 196(37.3)$ & $777(31.4)$ & $419(57.2)$ \\
\hline $20,000-40,000$ & $927(28.9)$ & $766(31.0)$ & $161(22.0)$ \\
\hline $40,000-60,000$ & $522(16.3)$ & $460(18.6)$ & $62(8.5)$ \\
\hline$>60,000$ & $559(17.5)$ & $469(19.0)$ & $90(12.3)$ \\
\hline \multicolumn{4}{|c|}{ Urban exposure status based on location at birth $\mathrm{N}(\%)$} \\
\hline $\begin{array}{l}\text { Rural area (rural } \\
\text { to urban migrant) }\end{array}$ & I,340 (4I.8) & $\mathrm{I}, 127(45.6)$ & $213(29.1)$ \\
\hline Urban area & $\mathrm{I}, 964(58.2)$ & $\mathrm{I}, 345(54.4)$ & $519(70.9)$ \\
\hline
\end{tabular}

Note: ${ }^{2}$ I Baht approximately equals US $\$ 1$. 
Table 4 Behavioral and biological/physiological risk factors for noncommunicable diseases in participants of the Chiang Mai University Health Worker Study

\begin{tabular}{|c|c|c|c|}
\hline & $\begin{array}{l}\text { Total } \\
\mathrm{N}=3,204\end{array}$ & $\begin{array}{l}\text { Female } \\
N=2,472\end{array}$ & $\begin{array}{l}\text { Male } \\
\mathrm{N}=732\end{array}$ \\
\hline \multicolumn{4}{|l|}{ Behavioral risk factors } \\
\hline Currently smoking: $\mathrm{N}(\%)$ & $199(6.2)$ & $7(0.3)$ & $192(26.3)$ \\
\hline $\begin{array}{l}\text { Alcohol consumption in } \\
\text { past } 12 \text { months: } \mathrm{N}(\%)\end{array}$ & $\mathrm{I}, 729(54.0)$ & $\mathrm{I}, 130(45.7)$ & $599(81.8)$ \\
\hline $\begin{array}{l}\text { Heavy drinking in past } \\
30 \text { days: }^{: ~} \mathrm{~N}(\%)\end{array}$ & $503(15.7)$ & $152(6.1)$ & $351(48.0)$ \\
\hline $\begin{array}{l}\text { Eating }>5 \text { portions of fruit } \\
\text { or vegetables per day: } \mathrm{N}(\%)\end{array}$ & $457(14.3)$ & $370(15.0)$ & $87(11.9)$ \\
\hline $\begin{array}{l}\text { Appropriate physical } \\
\text { activity: }{ }^{b} N(\%)\end{array}$ & $\mathrm{I}, 668(52.1)$ & $\mathrm{I}, 202(48.6)$ & $466(63.7)$ \\
\hline \multicolumn{4}{|c|}{ Biological and physiological risk factors } \\
\hline Mean SBP in $\mathrm{mmHg}(\mathrm{SD})$ & | $16 . \mid(15.5)$ & II2.9 (I4.2) & I26.8 (|4.9) \\
\hline Mean DBP in $\mathrm{mmHg}(\mathrm{SD})$ & $73.9(11.4)$ & $71.7(10.6)$ & $81.0(11.2)$ \\
\hline $\begin{array}{l}\text { High blood pressure } \\
\mathrm{SBP} \geq 140 \text { or } \mathrm{DBP} \geq 90 \text { : } \\
\mathrm{N}(\%)\end{array}$ & $357(11.1)$ & $180(7.3)$ & $177(24.2)$ \\
\hline \multicolumn{4}{|l|}{ Obesity: N (\%) } \\
\hline Normal: BMI $<23$ & $\mathrm{I}, 658(5 \mathrm{I} .7)$ & $\mathrm{I}, 42 \mathrm{I}(57.5)$ & $237(32.4)$ \\
\hline Overweight: BMI 23-25 & $602(18.8)$ & $424(17.1)$ & $178(24.3)$ \\
\hline Obese I: BMI 25-30 & $732(22.9)$ & $484(19.6)$ & $248(33.9)$ \\
\hline Obese II: BMI > 30 & $212(6.6)$ & $143(5.8)$ & $69(9.4)$ \\
\hline $\begin{array}{l}\text { Mean WC in centimeters } \\
\text { (SD) }\end{array}$ & $75.4(10.8)$ & $72.9(9.7)$ & $83.7(10.0)$ \\
\hline $\begin{array}{l}\text { Truncal obesity } N(\%) \\
(\mathrm{WC}>90 \mathrm{~cm} \text { in men and } \\
>80 \mathrm{~cm} \text { in women) }\end{array}$ & $659(20.6)$ & $500(20.2)$ & $159(21.7)$ \\
\hline $\begin{array}{l}\text { Mean fasting blood } \\
\text { glucose in mg/dL (SD) }\end{array}$ & $91.0(16.2)$ & $89.3(14.0)$ & $96.6(21.1)$ \\
\hline $\begin{array}{l}\text { High fasting blood glucose } \\
(\geq 126 \mathrm{mg} / \mathrm{dL}): N(\%)\end{array}$ & $73(2.3)$ & $36(1.5)$ & $37(5.1)$ \\
\hline Mean LDL in mg/dL (SD) & $|3| .0(35.5)$ & $129.6(34.0)$ & I36.0 (39.6) \\
\hline $\begin{array}{l}\text { High LDL } \geq 160 \mathrm{mg} / \mathrm{dL}: \\
\mathrm{N}(\%)\end{array}$ & $614(19.2)$ & $413(16.7)$ & $201(27.5)$ \\
\hline Mean HDL in mg/dL (SD) & $58.5(13.3)$ & $60.5(12.8)$ & $52.0(12.8)$ \\
\hline $\begin{array}{l}\text { Low } \mathrm{HDL}<50 \mathrm{mg} / \mathrm{dL} \text { in } \\
\text { women and }<40 \mathrm{mg} / \mathrm{dL} \text { in } \\
\text { men: } \mathrm{N}(\%)\end{array}$ & $578(18.1)$ & $481(19.5)$ & $97(13.3)$ \\
\hline $\begin{array}{l}\text { Mean triglycerides in } \\
\mathrm{mg} / \mathrm{dL}(\mathrm{SD})\end{array}$ & $102.2(96.0)$ & $87.1(81.6)$ & $153.2(120.5)$ \\
\hline $\begin{array}{l}\text { High triglycerides } \\
\geq 150 \mathrm{mg} / \mathrm{dL}: \mathrm{N}(\%)\end{array}$ & $504(15.7)$ & $228(9.2)$ & $276(37.8)$ \\
\hline \multicolumn{4}{|c|}{$\begin{array}{l}\text { Notes: }{ }^{2} \mathrm{~A} \text { heavy drinking pattern is defined as having more than five standard drinks } \\
\text { per sitting for men and four standard drinks per sitting for women; }{ }^{\text {throughout }} \\
\text { the week, an adult should do at least } 75 \text { minutes of vigorous-intensity physical } \\
\text { activity or } 150 \text { minutes of moderate-intensity physical activity or the equivalent of } \\
600 \text { metabolic equivalent minutes. }\end{array}$} \\
\hline $\begin{array}{l}\text { Abbreviations: BMI, body ma } \\
\text { density lipoprotein; LDL, low-de } \\
\text { waist circumference; SD, standa }\end{array}$ & $\begin{array}{l}\text { s index; DBP, di } \\
\text { nsity lipoprotein } \\
\text { d deviation. }\end{array}$ & stolic blood pres & $\begin{array}{l}\text { sure; HDL, high- } \\
\text { d pressure; WC, }\end{array}$ \\
\hline
\end{tabular}

(Table 4). Mean SBP and DBP were $126.8 \mathrm{mmHg}$ and 81.0 mmHg, respectively. About $11.1 \%$ of the participants had high blood pressure ( $\mathrm{SBP} \geq 140 \mathrm{mmHg}$ or $\mathrm{DBP} \geq 90 \mathrm{mmHg}$ ). Mean BMI was $23.4 \mathrm{~kg} / \mathrm{m}^{2}$ (standard deviation [SD] =4.1) in men and $23.0 \mathrm{~kg} / \mathrm{m}^{2}(\mathrm{SD}=4.0)$ in women. Overall, almost $30 \%$ were considered to be obese (BMI $\geq 25 \mathrm{~kg} / \mathrm{m}^{2}$ ). Mean FBG was $96.6 \mathrm{mg} / \mathrm{dL}(\mathrm{SD}=21.0$ ) Only $2.3 \%$ had high FBG ( $\geq 126 \mathrm{mg} / \mathrm{dL}$ ) and the most common abnormal lipid profile was high LDL ( $\mathrm{LDL} \geq 160 \mathrm{mg} / \mathrm{dL}$ ), which was found in $19.2 \%$ of participants (Table 4 ).

\section{Discussion}

This paper describes the protocol, response rates, and characteristics of the study population in the CMU Health Worker Study. A study of health care workers offered three potential advantages toward understanding NCDs in Thailand. The first advantage was the potential for a migration study: ie, the study of health effects of people moving from a rural to an urban area to work. The mechanisms or pathways by which sociocultural/ environmental exposures influence NCD risk factors could be explored using a migration study, as changes in environmental exposures can be documented. ${ }^{24}$ Most health personnel have moved since birth and early life, whether for education or employment purposes. ${ }^{25}$ Second, a study of health personnel allowed the investigators to control for access to care. Access to care is potentially a key confounder toward understanding the development of NCDs in Thailand. ${ }^{3}$ Lastly, a study of health personnel allowed easy access to laboratory and clinical investigations and potential for long-term follow-up. This enables ascertainment of a number of clinical outcomes and provides potential for future studies focusing on therapeutic and prognostic issues related to NCDs.

Many factors contributed to the completion of the survey. The pilot data from 2008 provided a valuable starting point for the study. The planning of the study began 1 year prior to data collection. This helped ensure that the electronic systems and supports were in place. The second recruitment period, with more aggressive advertising, allowed us to enroll and recruit populations with an initially low response rate. The data collection process, especially during the second process (interview, examination, and laboratory investigation), was considered to be time consuming. Two pilot runs (of the second part of the data collection process) were conducted to ensure smooth running and help calculate the manpower needed to keep the entire process between 30 minutes and 45 minutes per participant, in order to fit the busy schedule of workers in a large teaching hospital. Participants were contacted up to three times if they had missed their original appointment for physical and laboratory examinations. Integrating a research component into a routinely offered service helped subsidize the cost of research and promoted mutual collaboration between researchers and hospital administrators. 
The study has some limitations that could influence the validity and generalizability of our results. Differential response rates among different sexes and occupational groups may have caused selection bias, which would limit the generalization to the actual source population. However, depending on the mechanism of the bias, multiple techniques such as restriction, stratification, or inverse probability weighting can be used to deal with selection bias or nonresponse bias in future analysis. ${ }^{26} \mathrm{An}$ occupational study could limit generalization to the Thai population, and the "healthy worker" effect is likely to underestimate most associations seen if seriously ill patients are less likely to be employed. Nonetheless, the relative risks within the study population are still valid. ${ }^{27}$

To our knowledge, there have been only two large cohorts from Thailand examining the transition and trends associated with chronic NCDs. The first is a cohort of workers from the Electricity Generating Authority of Thailand, ${ }^{28}$ who looked at the trends in known cardiovascular risk factors and their association with all cause mortality and cardiovascular mortality. The authors stated that the study's main strength was in the breadth of biological markers available and the detailed verification of mortality and causes of mortality. However, there were limited data on behavioral factors (only smoking and alcohol consumption) and population level influences, such as urbanization. The second cohort is a study of Sukhothai Thammathirat Open University students. ${ }^{29}$ Its aim was to look at Thai health transition. The main aim was to study how the proximal and distal determinants of health influence health outcomes. Although both population determinants and detailed individual determinants were collected, no biological samples were taken. Our study could help provide linking evidence between the two large cohorts in Thailand and enhance the understanding of NCDs in Thailand.

If current patterns of economic development toward higher income, better education, and access to care in Thailand continue, our study could provide useful information on the development of NCDs as the rest of the country becomes more developed.

\section{Acknowledgments}

The authors would like to thank Shah Ebrahim, Anne Mills, Isabel Silva, Caroline Free, and Oona Campbell for their input during the conception and design of the project. The authors would like to thank the Faculty of Medicine of Chiang Mai University and the Research Institute for Health Sciences of Chiang Mai University for their support of the project and for lending valuable manpower and resources to help make this study possible. We would like to thank the Health Promotion Unit and all members of the research team involved with data collection and data entry. Lastly, we would like to thank all the participants who participated in our study. Authors' contributions: $\mathrm{CA}, \mathrm{PD}$, and $\mathrm{DN}$ were responsible for conception and design of the study. CA, AW, RU, and DN were responsible for development of the protocol. CA, AW, and WJ were responsible for coordination of the fieldwork. CA, PD, and DN are lead investigators for objectives 1 and 2 of the study. AW and RU are lead investigators for objective 3. WJ and SL are lead investgators for objective 4. All authors were responsible for acquisition of data. CA was responsible for initial analysis of the data and interpretation of the data and drafted the manuscript. All authors reviewed and approved the final manuscript.

\section{Disclosure}

Funding for the fieldwork was provided by the Faculty of Medicine Research Fund of Chiang Mai University. CA is funded by the Staff Development Fund of Chiang Mai University. The funders had no role in study design, data collection and analysis, decision to publish, or preparation of the manuscript. The authors have no further conflicts of interest in this work.

\section{Reference}

1. Dans A, Ng N, Varghese C, Tai ES, Firestone R, Bonita R. The rise of chronic non-communicable diseases in southeast Asia: time for action. Lancet. 2011;377(9766):680-689.

2. World Health Organization. Global Status Report on Noncommunicable Disease. Geneva, Switzerland: World Health Organization; 2010.

3. Angkurawaranon C, Wattanatchariya N, Doyle P, Nitsch D. Urbanization and non-communicable disease mortality in Thailand: an ecological correlation study. Trop Med Int Health. 2013;18(2):130-140.

4. Yiengprugsawan V, Caldwell BK, Lim LL-Y, Seubsman S-A, Sleigh AC. Lifecourse Urbanization, Social Demography, and Health Outcomes among a National Cohort of 71,516 Adults in Thailand. International Journal of Population Reserach. 2011;2011:pii: 464275.

5. Sritara P, Cheepudomwit S, Chapman N, et al. Twelve-year changes in vascular risk factors and their associations with mortality in a cohort of 3499 Thais: the Electricity Generating Authority of Thailand Study. Int J Epidemiol. 2003;32(3):461-468.

6. Dye C. Health and urban living. Science. 2008;319(5864):766-769.

7. Woodward D, Drager N, Beaglehole R, Lipson D. Globalization and health: a framework for analysis and action. Bull World Health Organ. 2001;79:875-881.

8. World Health Organization. Preventing Chronic Diseases: A Vital Investment. Geneva, Switzerland: World Health Organization; 2005.

9. Thongtong P, Angkurawaranon C, Yavichai S, Thammasarot J, Bangsinthu S. Health survey of personnel in Faculty of Medicine, Chiang Mai University. Chiang Mai Medical Journal. 2008;47(Suppl 3):29.

10. Maslach C, Jackson SE, Leiter MP. Maslach Burnout Inventory Manual. Palo Alton, CA: Consulting Psychologists Press; 1996.

11. WHO Assist Working Group. The Alcohol, Smoking and Substance Involvement Screening Test (ASSIST): development, reliability and feasibility. Addiction. 2002;97(9):1183-1194. 
12. Kroenke K, Spitzer RL, Williams JB. The PHQ-9: validity of a brief depression severity measure. J Gen Intern Med. 2001;16(9):606-613.

13. Jenkinson C, Stewart-Brown S, Petersen S, Paice C. Assessment of the SF-36 version 2 in the United Kingdom. J Epidemiol Community Health. 1999;53(1):46-50.

14. World Health Organization. The WHO STEPwise approach to chronic disease risk factor surveillance (STEPS). Available from: http://www. who.int/chp/steps. Accessed July 2, 2014.

15. United Nations, Department of Economic and Social Affairs, Population Division. World Urbanization Prospects: The 2011 Revision. New York: United Nations; 2012.

16. Bull FC, Maslin TS, Armstrong T. Global Physical Activity Questionnaire (GPAQ): nine country reliability and validity study. J Phys Act Health. 2009;6(6):790.

17. Kanazawa M, Yoshiike N, Osaka T, Numba Y, Zimmet P, Inoue S. Criteria and classification of obesity in Japan and Asia-Oceania. Asia Pacific Clinical Nutrition Society. 2002;11:S732-S737.

18. Aekplakorn W, Chariyalertsak S, Kessomboon P, et al. Prevalence and management of diabetes and metabolic risk factors in Thai adults: the Thai National Health Examination Survey IV, 2009. Diabetes Care. 2011;34(9):1980-1985.

19. Lim L, Seubsman S-A, Sleigh A. Thai SF-36 health survey: tests of data quality, scaling assumptions, reliability and validity in healthy men and women. Health Qual Life Outcomes. 2008;6(1):52.

20. Lotrakul M, Sumrithe S, Saipanish R. Reliability and validity of the Thai version of the PHQ-9. BMC Psychiatry. 2008;8(1):46.
21. Humeniuk R, Ali R, Babor TF, et al. Validation of the Alcohol, Smoking and Substance Involvement Screening Test (ASSIST). Addiction. 2008;103(6):1039-1047.

22. Kijjanon N, Jongjareonkumchok A, Masnaragorn P. Burnout among staff nurses working in intensive care units. Ramathibodi Nursing Journal. 2009;15(1):86-97.

23. Mishra G, Nitsch D, Black S, De Stavola B, Kuh D, Hardy R. A structured approach to modelling the effects of binary exposure variables over the life course. Int J Epidemiol. 2009;38(2):528-537.

24. Ebrahim S, Kinra S, Bowen L, et al. The effect of rural-to-urban migration on obesity and diabetes in India: a cross-sectional study. PLoS Med. 2010;7(4):e1000268.

25. Pagaiya N, Noree T. Thailand's Health Workforce: A Review of Challenges and Experience. Washington, DC: The International Bank for Reconstruction and Development/The World Bank; 2009.

26. Hernan MA, Hernandez-Diaz S, Robins JM. A structural approach to selection bias. Epidemiology. 2004;15(5):615-625.

27. Li CY, Sung FC. A review of the healthy worker effect in occupational epidemiology. Occup Med (Lond). 1999;49(4):225-229.

28. Vathesatogkit P, Woodward M, Tanomsup S, et al. Cohort profile: the electricity generating authority of Thailand study. Int $J$ Epidemiol. 2012;41(2):359-365.

29. Sleigh AC, Seubsman Sa, Bain C. Cohort profile: the Thai cohort of 87 134 Open University students. Int J Epidemiol. 2008;37(2):266-272.
Clinical Epidemiology

\section{Publish your work in this journal}

Clinical Epidemiology is an international, peer-reviewed, open access journal focusing on disease and drug epidemiology, identification of risk factors and screening procedures to develop optimal preventative initiatives and programs. Specific topics include: diagnosis, prognosis, treatment, screening, prevention, risk factor modification, systematic

\section{Dovepress}

reviews, risk \& safety of medical interventions, epidemiology \& biostatical methods, evaluation of guidelines, translational medicine, health policies \& economic evaluations. The manuscript management system is completely online and includes a very quick and fair peer-review system, which is all easy to use. 